\title{
COGNITIVE IMPROVEMENT AFTER TREATMENT OF DEPRESSIVE SYMPTOMS IN THE ACUTE PHASE OF STROKE
}

\author{
Samuel Simis' ${ }^{1}$ Ricardo Nitrini
}

\begin{abstract}
The outcome of antidepressant treatment for depressive symptoms and cognitive impairment at the acute phase of stroke is controversial. We investigated 93 patients, treating with citalopram 36 with seve redepressive symptoms (HAM-D: Hamilton Depression Rating Scale $\geq 18$ ), whilst 19 patients with mild dep ressive symptoms, and 38 non-depressed patients, remained untreated. At baseline (two weeks after stroke), patients with severe depressive symptoms had lower scores in total Dementia Rating Scale (DRS) and in the attention and memory DRS subscales, than the non-depressed patients $(p \leq 0.001)$. At the end of the three-month follow-up period, these diff e rences had disappeared, but patients initially with mild depressive symptoms had higher HAM-D scores than the non-depressed patients $(p=0.015)$, and lower scores in DRS attention and memory subscales $(p<0.01)$, than the patients treated with citalopram. Treatment was associated with improved mood, memory and attention, and a placebo-controlled study on the tre atment of mild depressive symptoms is warranted.
\end{abstract}

KEY WORDS: post-stroke depression, treatment, vascular cognitive impairment, vascular dementia.

\section{Melhora cognitiva com tratamento antidepressivo na fase aguda do acidente vascular cerebral}

RESUMO - Os resultados do tratamento com antidepressivo para os sintomas depressivos e comprometimento cognitivo da fase aguda do acidente vascular cerebral não estão estabelecidos. Investigamos 93 pacientes, 36 com sintomas depressivos graves (HAM-D: Escala de Depressão de Hamilton $\geq 18$ ) foram tratados com citalopram, enquanto 19 pacientes com sintomas depressivos leves e 38 não-deprimidos não foram tratados. Ao início do tratamento (duas semanas depois do icto), pacientes com sintomas depressivos graves tinham escores mais baixos na Escala de Avaliação de Demência (DRS) total e nas subescalas de atenção e de memória da DRS do que os pacientes não-deprimidos $(p \leq 0,001)$. Ao fim de três meses de acompanhamento essas diferenças tinham desaparecido, mas pacientes que inicialmente tinham sintomas depressivos leves passaram a ter escores mais altos no HAM-D do que os não-deprimidos $(p=0,015)$, e escores mais baixos nas subescalas de atenção e memória da DRS $(p<0,01)$ do que os pacientes tratados com citalopram. 0 tratamento associou-se a melhora de humor, memória e atenção, e demonstra que é necessário um estudo controlado com placebo para o tratamento de sintomas depressivos leves.

PALAVRAS-CHAVE: acidente vascular cerebral, depressão, tratamento, comprometimento cognitivo vascular, demência vascular.

Depressive symptoms are frequent after stroke and post-stroke depression is associated with excess disability, cognitive impairment, and mortality ${ }^{1,2}$. Treatment of post-stroke depression improves mood, but it is still unsettled whether the use of antidepressants may improve cognition or recovery after stroke ${ }^{3}$. Post-stroke depression has been diagnosed either in the acute as in the chronic phase after stroke, and some of the diffe rences between the results of studies may be due to grouping together two probably different conditions ${ }^{2}$. Diagnosis of depression in the acute phase of stroke may be very difficult because symptoms that are associated with depression such as apathy, lack of interest or pleasure in activities, and even crying may be either attributed to stroke or to depression in the first days or weeks following a stroke ${ }^{2}$.

The optimal start point for treatment of depressive symptoms after stroke has yet to be established. In a double-blind, placebo-controlled study, the effect

\footnotetext{
${ }^{1}$ Assistant Professor of Neurology, Catholic University of São Paulo, Sorocaba SP, Brazil; ${ }^{2}$ Associate Professor of Neurology, Department of Neurology, University of São Paulo School of Medicine, São Paulo SP, Brazil. Support: Citalopram was supplied by ScheringPlough, who played no further part in the study's design, running or data management.
}

Received 3 October 2005, received in final form 11 January 2006. Accepted 16 February 2006. 
of fluoxetine could not be ascertained within the first th re months after stroke because spontaneous recovery masked any possible benefits of antidepressant tre atmen $\mathrm{t}^{4}$. Post-stroke cognitive impairment is also very common, where its cause is probably multi-factorial ${ }^{5}$. The role of mood changes in the genesis of post-stroke cognitive impairment remains controversial ${ }^{6,7}$, and there is also controversy regarding the outcome of cognitive impairment following mood improvement ${ }^{6,8}$. A recent systematic review of ph a rmacological therapies of depression after stroke concluded that there is no evidence of benefit of antidepressants in improving cognitive function ${ }^{3}$. Most of the studies have analyzed the effects of the tre atment for depression based on the general intellectual function only, without focusing on specific cognitive domains ${ }^{6-9}$.

The aim of this study was to investigate the outcome of both depressive symptoms and cognitive impairment following antidepressant treatment in the acute phase of ischemic stroke, seeking to identify the cognitive domains most improved by the treatment.

\section{METHOD}

From 18 January 1998 to 30 July 2000, 171 patients with acute supratentorial ischemic stroke who had been consecutively admitted to the Emergency Room of the Catholic University of São Paulo Hospital, in Sorocaba, São Paulo State, Brazil, were evaluated for inclusion in the study. After evaluation, and according to inclusion and exclusion criteria, 73 patients were excluded from the study (aphasia that p recluded neuropsychological evaluation : 21 ; absence of evidence of stroke on CT-scan: 17; previous stroke based on information or in CT-scan: 14; Glasgow scale under 13: 12; transient ischemic attack (TIA): 8; Binswanger disease: 1). Another five patients refused to participate; giving a final sample comprising 93 patients.

The patients were examined on the day after admission to the hospital (visit 1), 14 days later (visit 2: baseline), and subsequently after 30 (visit 3), 60 (visit 4) and 90 (visit 5) days.

Cognitive impairment was assessed with the Mattis Dementia Rating Scale (DRS) ${ }^{10,11}$ by a psychologist blind to the clinical data. The severity of the depressive symptoms was measured by the psychologist using the 21-item Hamilton Rating Scale for Depression (HAM-D) ${ }^{12}$. CT- scans were performed between day 3 and day 7, and were analyzed by the same neuroradiologist, who did not have access to the clinical assessments. Localization and volume of the lesions were estimated using an atlas of the human brain ${ }^{13}$.

At baseline, the patients were classified into those with severe depressive symptoms (HAM-D $\geq 18 ; N=36$ ), with mild depressive symptoms (HAM-D scores 13-17; $N=19$ ) and nondepressed patients (HAM-D scores < 13; N=38).

Patients with severe depressive symptoms were tre at- ed with citalopram $10 \mathrm{mg}$ per day starting after baseline. This dose was increased to $20 \mathrm{mg}$ per day after 10 days. The dose was kept at $20 \mathrm{mg}$ per day, or was increased to $40 \mathrm{mg}$ per day if HAM-D $\geq 18$ on visit 3 . Both patients with mild depressive symptoms and non-depressed patients were not treated with citalopram.

Informed consent was obtained from all subjects and/or their relatives. The study was approved by the Ethics Committee of Catholic University of São Paulo.

Statistical analysis were perf o rmed using the chi-square test for categorical variables and analysis of variance with a fixed value (F) for quantitative variables. Differences between groups and visits were evaluated using multiple comparison tests with the Bonferroni method. The last observation carried forwa rd (LOCF) method was used when necessary. SPSS for Windows, version 10.0 (SPSS Inc.), was used for the statistical analysis. The value of significance accepted was 0.05 .

\section{RESULTS}

Ages of the patients with severe depressive symptoms (65.8 \pm 10.4 ; range $44-86)$, mild depressive symptoms $(63.7 \pm 12.8$; range $40-82)$, and non-depressed patients $(63.5 \pm 14.1$; range $37-90)$ did not differ $(p=$ 0.699). Other characteristics are shown in Table 1.

Lesions were larger in the patients with severe depressive symptoms, more often being subcort ical and anterior, than in the other two groups. The side of the hemispheric lesion was not different in the three groups (Table 2).

During the follow-up, two patients with mild depressive symptoms at baseline had deteriorated to severe depressive symptoms by visit 3 , and were treated with citalopram. Two patients died during the follow-up, one of them belonging to the group treated with citalopram, whilst there were two dropouts (also one in the citalopram group). Two additional patients, not treated with citalopram, had myocardial infarction and stroke respectively. For the analysis of the outcome, the results of the observations at baseline of these eight patients were carried forward.

The three groups manifested different evolutions from visits 2 to 5 in HAM-D ( F=16.49; $p<0.001)$ and in DRS total scores $(F=7.32 ; p<0.001)$, as well as in DRS attention ( $F=9.70 ; p<0.001)$, memory $(F=10.84 ; p<$ $0.001)$ and in initiation-perseveration subscale score $s$ $(F=2.96 ; p=0.009)$. On all these scales and subscales, the percentages of variation of scores between visits 2 and 5 were higher in patients with severe depressive symptoms. However, the evolutions of the three groups were not diff e rent for construction and conceptualization subscale scores.

Mean scores at baseline, and at the end of the follow-up are shown in Table 3 and in the Figure. 
Table 1. Demographic data and psychiatric antecedents of the three groups of patients.

\begin{tabular}{|c|c|c|c|c|c|c|c|c|c|}
\hline & \multicolumn{2}{|c|}{$\begin{array}{l}\text { Patients with } \\
\text { severe depressive } \\
\text { symptoms }\end{array}$} & \multicolumn{2}{|c|}{$\begin{array}{l}\text { Patients with } \\
\text { mild depressive } \\
\text { symptoms }\end{array}$} & \multicolumn{2}{|c|}{$\begin{array}{l}\text { Non-depressed } \\
\text { patients }\end{array}$} & \multicolumn{2}{|c|}{ Total } & \multirow[t]{2}{*}{$\mathrm{p}$} \\
\hline & $\mathrm{N}$ & $\%$ & $\mathrm{~N}$ & $\%$ & $\mathrm{~N}$ & $\%$ & $\mathrm{~N}$ & $\%$ & \\
\hline Gender & & & & & & & & & 0.087 \\
\hline Female & 21 & 58.3 & 7 & 36.8 & 13 & 34.2 & 41 & 44.1 & \\
\hline Total & 36 & 100 & 19 & 100 & 38 & 100 & 93 & 100 & \\
\hline Literacy level & & & & & & & & & $>0.2$ \\
\hline Illiterates & 15 & 41.7 & 9 & 47.4 & 10 & 26.3 & 34 & 36.6 & \\
\hline Total & 36 & 100 & 19 & 100 & 38 & 100 & 93 & 100 & \\
\hline \multicolumn{10}{|l|}{ Personal history } \\
\hline of depression & & & & & & & & & $<0.001$ * \\
\hline Present & 19 & 52.8 & 4 & 21.1 & 2 & 5.3 & 25 & 26.9 & \\
\hline Total & 36 & 100 & 19 & 100 & 38 & 100 & 93 & 100 & \\
\hline \multicolumn{10}{|l|}{ Family history } \\
\hline of depression & & & & & & & & & 0.060 \\
\hline Present & 9 & 25.0 & 3 & 15.8 & 2 & 5.3 & 14 & 15.1 & \\
\hline Total & 36 & 100 & 19 & 100 & 38 & 100 & 93 & 100 & \\
\hline
\end{tabular}

* Difference between group 1 and the other two groups.

Table 2. Characteristics of the ischemic lesion of the three groups of patients.

\begin{tabular}{|c|c|c|c|c|c|c|c|c|c|}
\hline & \multicolumn{2}{|c|}{$\begin{array}{c}\text { Patients with } \\
\text { severe depressive } \\
\text { symptoms }\end{array}$} & \multicolumn{2}{|c|}{$\begin{array}{l}\text { Patients with } \\
\text { mild depressive } \\
\text { symptoms }\end{array}$} & \multicolumn{2}{|c|}{$\begin{array}{c}\text { Non-depressed } \\
\text { patients }\end{array}$} & \multicolumn{2}{|c|}{ Total } & \multirow[t]{2}{*}{$\mathrm{p}$} \\
\hline & $\mathrm{N}$ & $\%$ & $\mathrm{~N}$ & $\%$ & $\mathrm{~N}$ & $\%$ & $\mathrm{~N}$ & $\%$ & \\
\hline \multicolumn{10}{|l|}{ Lesion size } \\
\hline Large & 27 & 75.0 & 5 & 26.3 & 7 & 18.4 & 39 & 41.9 & $0.001 *$ \\
\hline Medium & 5 & 13.9 & 7 & 36.8 & 10 & 26.3 & 22 & 23.7 & \\
\hline Small & 4 & 11.1 & 7 & 36.8 & 21 & 55.3 & 32 & 34.4 & \\
\hline Total & 36 & 100 & 19 & 100 & 38 & 100 & 93 & 100 & \\
\hline \multicolumn{10}{|l|}{ Lesion location } \\
\hline Right hemisphere & 15 & 41.7 & 12 & 63.2 & 23 & 60.5 & 50 & 53.8 & 0.174 \\
\hline Left hemisphere & 21 & 58.3 & 7 & 36.8 & 15 & 39.5 & 43 & 46.2 & \\
\hline Total & 36 & 100 & 19 & 100 & 38 & 100 & 93 & 100 & \\
\hline Cortical & 19 & 52.8 & 16 & 84.2 & 32 & 84.2 & 67 & 72.0 & $0.005^{*}$ \\
\hline Subcortical & 17 & 47.2 & 3 & 15.8 & 6 & 15.8 & 26 & 28.0 & \\
\hline Total & 36 & 100 & 19 & 100 & 38 & 100 & 93 & 100 & \\
\hline Anterior & 28 & 77.8 & 4 & 21.1 & 18 & 47.4 & 50 & 53.8 & $0.001 *$ \\
\hline Posterior & 8 & 22.2 & 15 & 78.9 & 20 & 52.6 & 43 & 46.2 & \\
\hline Total & 36 & 100 & 19 & 100 & 38 & 100 & 93 & 100 & \\
\hline
\end{tabular}

* Difference between group 1 and the other two groups.

In HAM-D, each group differed from one another at baseline $(p<0.001)$, whilst at visit 5 , only the patients with mild depressive symptoms differed from the non-depressed patients $(p=0.015)$.

At baseline, the mean scores of the patients with severe depressive symptoms diff e red from those of the non-depressed patients on total DRS $(p=0.001)$, and in the attention $(p<0.001)$, memory $(p=0.001)$ and initiation-perseveration $(p=0.003)$ DRS subscales. At visit 5, these differences were no longer present, 
Table 3. Mean scores (SD) of the three groups of patients in visit 2 (baseline), at the end of the follow-up, and percentage of vari ation $(\Delta \%)$ from visit 2 to visit 5.

\begin{tabular}{llccc}
\hline Scales & Groups & Visit 2 & Visit 5 & $\Delta \%($ V5-V2) \\
\hline HAM-D & With severe depressive symptoms & $21.0(2.2)$ & $10.9(3.3)$ & -48.1 \\
& With mild depressive symptoms & $14.9(1.1)$ & $12.1(2.8)$ & -18.2 \\
& Non-depressed & $9.2(2.4)$ & $9.2(4.3)$ & -1.7 \\
DRS - Total & With severe depressive symptoms & $75.3(28.9)$ & $110.0(18.3)$ & $70.5(88.8)$ \\
& With mild depressive symptoms & $85.7(21.0)$ & $96.2(18.4)$ & $14.0(12.5)$ \\
& Non-depressed & $100.5(27.0)$ & $109.5(26.2)$ & $11.1(13.6)$ \\
DRS - Memory & With severe depressive symptoms & $10.6(6.2)$ & $19.8(4.7)$ & $250.2(470.3)$ \\
& With mild depressive symptoms & $12.7(5.2)$ & $14.3(5.2)$ & $16.9(24.9)$ \\
& Non-depressed & $16.5(6.7)$ & $17.6(6.8)$ & $8.2(19.4)$ \\
DRS - Attention & With severe depressive symptoms & $23.8(7.7)$ & $35.8(2.1)$ & $68.2(64.1)$ \\
& With mild depressive symptoms & $27.1(6.0)$ & $29.6(4.8)$ & $11.2(14.7)$ \\
\hline
\end{tabular}

DRS, Dementia Rating Scale; HAM-D: Hamilton Rating Scale for Depression; V2: visit 2 (or baseline); V5: visit 5 (end of the follow-up).

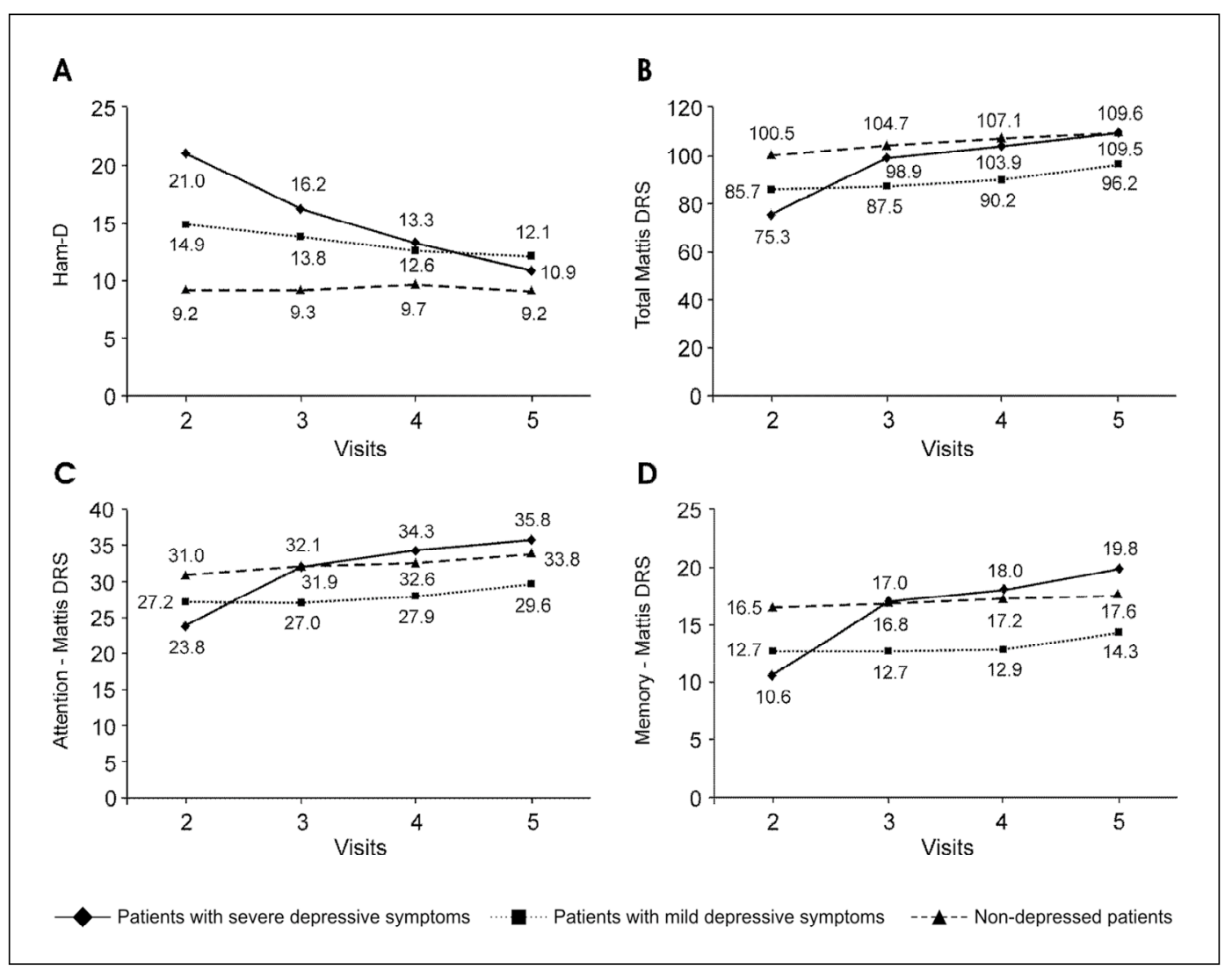

Figure Mean scores of the three groups of patients: $(A)$ in the Hamilton Rating Scale for Depression (Ham$D),(B)$ in the total Dementia Rating Scale (DRS) and (C) in the attention and (D) memory subscales of DRS during the follow-up.

but the group of patients with mild depressive symptoms showed lower mean scores in the attention DRS subscale when compared to both the non-depressed $(p=0.001)$, and citalopram-treated patients $(p<0.001)$, along with lower mean scores in the memory DRS subscale when compared to the citalopram-treated patients $(p=0.003)$, and a trend toward lower mean score in total DRS when compared to both the nondepressed (0.097) and citalopram-treated patients $(p=0.098)$. 


\section{DISCUSSION}

Treatment with antidepressant was associated with improvement of both mood and cognition in this study. The cognitive improvement observed in the patients treated with citalopram in the acute phase of stroke strengthens the hypothesis that mood changes play a significant role in cognitive impairment after stroke, but also that its origin is multifactorial, given that after improvement of depressive symptoms, mean DRS scores still remained low. The low mean scores of the cognitive tests in this study are also related to the low educational level of our patients.

Although it is conceivable depressive symptoms and cognitive impairment might have improved spontaneously without treatment after the acute phase of the stroke, the evolution shown by our patients with mild depressive symptoms suggests this would not have been the case. Mean HAM-D scores for this $g$ roup decreased spontaneously, but not to the same extent as the treated group, and at the end of the follow-up, scores were higher than those of the nonde pressed patients. Besides, it is noteworthy that at the end of follow-up, the patients with mild depressive symptoms had lower mean scores in the attention and memory DRS subscales when compared to the patients who had been treated with antidepre ssant.

Citalopram was the chosen antidepressant agent because this selective serotonin reuptake inhibitor has a favorable profile of side effects, and because it had shown good results in a previous study ${ }^{14}$. In other recent studies, citalopram has shown good efficacy and lack of severe side effects in the treatment of post-stroke depression ${ }^{15,16}$.

We have described our patients as having "depressive symptoms", and have endeavored to avoid the use of the word "depression", because it is very difficult or even impossible, to rely on standard criteria for depression such as the DSM-IV ${ }^{17}$, in the acute phase of stroke ${ }^{2}$.

It should be noted that the mean score of the group classified as having severe depressive symptoms (21.0 \pm 2.2$)$ was not as high as the scores observed in endogenous major depression, or even in depre ssion in the non-acute phase of stroke ${ }^{18,19}$. However, only about $40 \%$ of our patients were considered nond e p ressed according to HAM-D scores, showing that mood changes are very common in the acute phase of stroke, albeit not very severe, as previously described in other studies ${ }^{20,21}$. Another factor that may have contributed to the high frequency of depressive symptoms in these patients is low education, which may be associated with a higher prevalence of depressive symptoms ${ }^{22,23}$.

Severedepressive symptoms were associated with larger, more frequently subcortical and anterior ischemic lesions in this study, in line with several ${ }^{24,25}$, but not all reports of post-stroke depression ${ }^{26}$. On the other hand, it was not associated with the side of the hemispheric lesion. The importance of the side of the lesion for the occurrence of post-stroke depression has yet to be ascertained ${ }^{27}$. It is important to note that we excluded 21 patients with aphasia, which may have had an influence on our results concerning the importance of the side of the lesion.

This study has several limitations. Magnetic re sonance imaging, particularly if including the diffusion method, would have had more sensitivity and specificity for the diagnosis of acute stroke and for the topographic correlation, than the CT-scan we used ${ }^{28}$. The low educational level of most of our patients may is another limitation, indicating the need to confirm these data for other populations. The most important limitation however, is the lack of a placebo a rm. However, when designing the study we conside red that it would be unethical to withhold the treatment for patients with severe depressive symptoms.

To conclude, our data suggest that treatment of depressive symptoms in the acute phase of stroke improves both mood and cognition and also indicate that a double-blind placebo-controlled study on the t reatment of mild depressive symptoms in the acute phase of stroke is warranted.

\section{REFERENCES}

1. Robinson RG. Poststroke depression: prevalence, diagnosis, treatment, and disease progression. Biol Psychiatry 2003;54:376-387.

2. Bogousslavsky J. Emotions, mood, and behavior after stroke. Stroke 2003;34:1046-1050.

3. Hackett ML, Anderson CS, House AO. Management of depression after stroke: a systematic review of pharmacological therapies. Stroke 2005;35:1098-1103.

4. Fruehwald S, Gatterbauer E, Rehak P, Baumhackl U. Early fluoxetine treatment of post-stroke depression; a three-month double-blind placebo-controlled study with an open-label long-term follow up. J Neurol 2003;250:347-351.

5. Pohjasvaara T, Erkinjuntti T, Ylikoski R, Hietanen M, Vataja R, Kaste M. Clinical determinants of poststroke dementia. Stroke 1998;29:75-81.

6. Andersen G, Vesterg a a rd K, Riis JO, Ingeman-Nielsen M. Dementia of depression or depression of dementia in stroke? Acta Psychiat Scand 1996;94:272-278.

7. Murata Y, Kimura M, Robinson RG. Does cognitive impairment cause post-stroke depression? Am J Geriatr Psychiatry 2000;8:310-317.

8. Narushima K, Chan KL, Kosier JT, Robinson RG. Does cognitive recovery after treatment of poststroke depression last? A 2-year follow-up of cognitive function associated with poststroke depression. Am J Psychiatry 2003;160:1157-1162.

9. Kimura M, Robinson RG, Kosier JT. Treatment of cognitive after postst roke depression: a double-blind treatment trial. Stroke 2000;31:14821486. 
10. Mattis S. Mental status examination for organic mental syndrome in the elderly patient. In: Bellak L, Karasu TB (eds). Geriatric psychiatry. New York: Grune and Stratton, 1976:77-121.

11. Porto CS, Fichman HC, Caramelli P, Bahia VS, Nitrini R. Brazilian version of the Mattis dementia rating scale: diagnosis of mild dementia in Alzheimer's disease. Arq Neuropsiquiatr 2003;61:339-345.

12. Hamilton MA. A rating scale for depression. J Neurol Neurosurg Psychiatry 1960;23:56-62.

13. Matsui T, Hirano A. An atlas of the human brain for computed tomography. Tokyo: Igaku-Shoin, 1978:164-189.

14. Andersen G, Vesterga ard K, Lauritzen L. Effective treatment of poststroke depression with the selective serotonin reuptake inhibitor citalopram. Stroke 1994;25:1099-1104.

15. Rampello L, Chiechio S, Nicoletti G, et al. Prediction of the response to citalopram and reboxetine in post-stroke depressed patients. Psychopharmacology (Berl) 2004;173:73-78.

16. Van de Meent H, Geurts AC, Van Limbeek J. Pharmacologic treatment of poststroke depression: a systematic review of the literature. Top Stroke Rehabil 2003;10:79-92.

17. American Psychiatric Association. Diagnostic and statistical manual of mental disorders. $4^{\text {th }}$ ed. Washington, DC: American Psychiatric Press, 1994.

18. Ramasubbu R. Relationship between depression and cerebrovascular disease: conceptual issues. J Affect Disord 2000;57:1-11.
19. Aströn M, Adolfsson R, Asplund K. Major depression in stroke patients: a 3-year longitudinal study. Stroke 1993;24:976-982.

20. Kellermann M, Fekete I, Gesztelyi R, et al. Screening for depressive symptoms in the acute phase of stroke. Gen Hosp Psychiatry 1999; 21:116-121.

21. BergA, Palomaki H, Lehtihalmes M, Lonnqvist J, Kaste M. Poststroke depression in acute phase after stroke. Cerebrovasc Dis 2001;12:14-20.

22. Patel V, Araya R, de Lima M, Ludemir A, Todd C. Women, poverty and common mental disorders in four restructuring societies. Soc Sci Med 1999;49:1461-1471.

23. Gazmararian J, Baker D, Parker R, Blazer DG. A multivariate analysis of factors associated with depression: evaluating the role of health literacy as a potential contributor. Arch Intern Med 2000;160;3307-3314.

24. House A, Dennis M, Mogridge L. Mood disorders in the year after stroke. Br J Psychiatry 1991;158:83-92.

25. Morris PLP, Robinson RG, Raphael B. Lesion location and post-stroke depression. J Neuropsychiatry Clin Neurosci 1996;8:399-403.

26. Carson AJ, MacHale S, Allen K, et al. Depression after stroke and lesion location: a systematic review. Lancet 2000;356:9224:122-126.

27. Bhogal SK, Teasell R, Foley N, Speechley M. Lesion location and poststroke depression: systematic review of the methodological limitations in the literature. Stroke 2004;35:794-802.

28. Oliveira-Filho J, Ay H, Schaefer PW, et al. Diffusion-weighted magnetic resonance imaging identifies the "clinically relevant" small-penetrator infarcts. Arch Neurol 2000;57:1009-1014. 